\title{
Dietary Knowledge and Practices among Non- Medical Staff at Babcock University in Ogun State, Nigeria
}

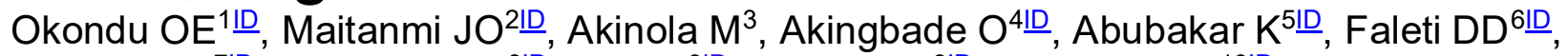

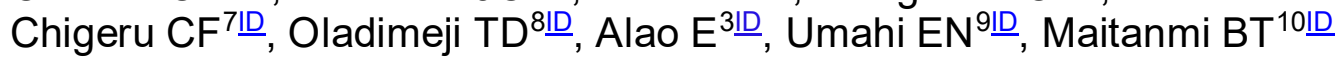

${ }^{1}$ Faculty of Education, Department of Human Kinetics and Health Education, Nnamdi Azikiwe University, Awka, Anambra State, Nigeria

${ }^{2}$ Department of Community/Public Health Nursing, Babcock University, Ilishan-Remo, Ogun State

${ }^{3}$ Department of Public Health, Babcock University, Ilishan-Remo, Ogun State, Nigeria

${ }^{4}$ The Nethersole School of Nursing, The Chinese University of Hong Kong

${ }^{5}$ University of Sheffield, South Yorkshire, England, United Kingdom

${ }^{6}$ Institute of Nursing Research, Nigeria

${ }^{7}$ Student Support Center, Babcock University, Ilishan-Remo, Ogun State, Nigeria

${ }^{8}$ Perioperative Nursing School, University College Hospital Ibadan, Oyo State Nigeria

${ }^{9}$ Department of Public Health, Taraba State University, Jalingo, Nigeria

${ }^{10}$ Department of Mental Health, Babcock University, Ilishan-Remo, Ogun State, Nigeria

ID: Orcid ID

Submitted: $28^{\text {th }}$ June 2021

Accepted: $10^{\text {th }}$ September 2021

Published: $30^{\text {th }}$ December 2021

\begin{abstract}
Objective: Good nutrition is important in promoting health and is dependent on the quality of food eaten. Little has been researched on the dietary practices among the workforce in Nigeria. This study aimed at assessing the dietary knowledge, practices, and factors influencing dietary practices and work productivity among the non-medical staff of Universities.

Methods: This is a descriptive cross-sectional survey of 398 non-medical staff of Babcock University who were selected using the multi-stage sampling technique. Data were analyzed using the Statistical Package for Social Sciences (SPSS 21) to compute frequency distributions, means, and standard deviations. Nutritional knowledge, dietary practices, and barriers to work productivity were assessed. Inferential statistical analysis was conducted using Pearson's correlation coefficient.

Results: The mean age among respondents was $38.68 \pm 11.04$, with the majority being female $54.6 \%$. of the respondents $(61.1 \%)$ of Yoruba origin, about three percentiles $(66 \%)$ were members of staff while $(34 \%)$ were faculty members. The computed level of knowledge and dietary-based practices scores were $(2.57 \pm 0.61)$ and (3.64 \pm 1.44$)$ respectively, indicating poor knowledge and dietary practices, while the barriers that influence work productivity among workers $(11.34 \pm 5.286)$ were high at $87.2 \%$. No significant association was found between nutritional knowledge and dietary practices of staff and faculty $(p=.154)$, but a significant association was found between dietary practices and work productivity of staff and faculty $(p=.019)$

Conclusion: Health education and promotion of good nutrition should be incorporated in the workplace, interventions that will improve work productivity among workers are also encouraged. This will culminate in a wellfed and healthy workforce.
\end{abstract}

Keywords: Nutrition, Knowledge, Dietary practice, Staff, Work productivity

Correspondence:

Akingbade, Oluwadamilare

The Nethersole School of Nursing,

The Chinese University of Hong Kong

+2348037811768, oakingbade@link.cuhk.edu.hk

(c) BUMJ. 2020 Open Access This article is distributed under the terms of the Creative Commons Attribution 4.0 International License

(http://creativecommons.org/licenses/by/4.0/), which permits unrestricted use, distribution, and reproduction in any medium, provided you give appropriate credit to the original author(s) and the source, provide a link to the Creative Commons license, and indicate if changes were made. The Creative Commons Public Domain Dedication waiver (http://creativecommons.org/publicdomain/zero/1.0/) applies to the data made available in this article, unless otherwise stated. 


\section{Plain English summary}

Adequate dietary knowledge and good dietary practice are important in living a healthy life and maintaining optimum work productivity. This study provides an insight into dietary knowledge and practice among the non-medical staff of Babcock University, Nigeria. We found that the dietary knowledge and practice were poor, and barriers to work productivity were high. This study suggested that good nutrition should be promoted at the workplace through health education.

\section{Background}

Many factors contribute to productivity in the workplace. One of such factors often neglected in the equation of attaining optimum workplace performance is food. While food is an essential component in adopting and maintaining a healthy lifestyle, it must be taken in the right proportion suitable for meeting the daily energy requirement especially in the workplace where many spend at least one-third of their daily hours $(1,2)$.

Nutrition is simply defined as the process of taking in food and using it for metabolism, growth, and repair (3). The need for proper nutrition cannot be overemphasized. In 2018, it was estimated that 820 million people did not get enough to eat (4). Similarly, the World Health Organization has stressed that the world is facing a double burden of malnutrition which includes undernutrition and overnutrition especially in lowand-middle-income countries (5). A study also reported poor nutritional status among citizens of many African countries, Nigeria inclusive (6). Proper dietary habit has been defined as the habitual decisions made by people regarding the food, they consume which should include all the classes of food in the right proportion (7). If this is done, the World Health Organization has observed that it will culminate in more productivity which will create more opportunities, thus breaking the cycles of poverty (5).

Poor dietary practices have been linked with poor productivity at work just as the International Labour Organization has stressed that poor diet on the job accounts for $20 \%$ of loss of productivity (8). Similarly, a report showed that unhealthy eating is linked with a $66 \%$ increase in loss of productivity (9). Not only will unhealthy eating habits reduce work productivity, but it has also been associated with conditions like diabetes, hypertension, osteoporosis, cardiovascular diseases and some cancers (10).

It is important to note that nutritional requirements vary from one individual to another (11). For instance, the nutritional requirement for a child will differ from that of an athlete, depending on the level of productivity. Similarly, that of a pregnant woman will be different from that of a middle-aged person. Productivity at work has been shown to decrease as a result of poor nutrition, and this contributes to feelings of tiredness, sluggishness, thus leading to inadequate energy for the body to function optimally $(5,11)$. Similarly, long hours of works without adequate portions of well-balanced meals will contribute to inefficiency and low work output, thus meeting the Key Performance Index (KPI) becomes a challenge for a work environment, and overall daily activity (12).

One of the ways to reduce intake of less nutritious foods is proper dissemination of information and clear labeling of products (13). Moreover, the demands of a workplace, in addition to poor nutritional health can lead to adverse psychological and physical health effects, consequently, hindering workplace productivity (12).

With these in mind, the study aimed to ascertain knowledge, dietary practices, and factors influencing dietary practices and work productivity among non-medical staff at Babcock University. We hypothesized that there is no significant relationship between nutritional knowledge and dietary practices of non-academic staff and faculty and between dietary practices and work productivity of members of staff of the University. Findings from this study will assist in developing interventions to promote optimal dietary practices concerning work productivity among the study population, the local and international communities.

\section{Methods}

Study design

This research was a descriptive cross-sectional study.

\section{Study Area}

Babcock University is a private Christian University owned and operated by the Seventhday Adventist Church in Nigeria. It is located equidistant between Ibadan and Lagos. The school which is located in lkenne local government is bounded in the North by Remo North local government, south by Sagamu local government, in the east by Odogbolu and ljebu North-East local governments, and in the west by Obafemi Owode local government. The schools of learning in Babcock University include the School of Science and Technology, Veronica 
Adeleke School of Social Sciences, School of Management Sciences, School of Computing and Engineering Sciences, College of Health and Medical Sciences, School of Education and Humanities, School of Law and Security Studies, School of Nursing Sciences, School of Public and Allied Health, and Academic Library. The divisions of the Staff members include Presidency Division, Academic Administration Division, Management Services Division, Financial Administration Division, Student Development Services Division, and Subsidiaries.

\section{Study Population}

This study included male and female academic and non-academic members of the staff of Babcock University. Inclusion criteria included those who were at least 18 years of age, and those who have worked for nothing less than 12 months in the university, while who were working part-time were excluded from the study.

\section{Sampling Technique}

All faculties except the College of Health and Medicine were purposively selected for this study. A random sampling technique was used to select departments from the faculties through a balloting system. Afterward, a convenience sampling technique was used to select members of staff from the relevant departments.

\section{Sample size estimation}

The sample size was calculated using the Cochran formula (14). A total of 384 respondents was obtained. $5 \%$ attrition rate was considered making 403 respondents. A total of 398 questionnaires were eventually retrieved.

\section{The instrument for Data collection}

Data were collected using a self-designed questionnaire, pre-tested and the calculated Cronbach's alpha coefficient was $80 \%$. The questionnaire was divided into four sections namely:

Section A: Socio-demographic characteristics. This included the age (as at last birthday), gender, school, ethnicity, and respondents' level of education.

Section B: Knowledge of nutrition. This section elicited the respondent's level of knowledge on nutrition information. Questions like "fruits must be taken before and after a meal" and "porridge, yam, bread are energy-rich foods?" were asked with options of 'Yes' and 'No'. knowledge questions had 10 items and knowledge score was computed from the item questions; $0-3$ as poor, 4-6 as average, and 7-10 as good knowledge respectively with mean and standard deviation score of $2.57 \pm 0.61$.

Section C: Dietary Practice section had 10 items and the practice score was computed from the item questions; with a mean and standard deviation of $3.64 \pm 1.44$. This section was on a Likert Scale with questions like frequency of reading food labels, eating breakfast, eating three square meals, seeking out nutrition information, and snacking on food. Always was scored as 4, Often as 3, Sometimes as 2, and Never as 1 on a scale of $10-40$. Scores $\geq 25$ were considered good practice and scores $<25$ were considered bad practice.

Section D: This section assessed barriers influencing work productivity. This was scored on a scale of 1-10 with 13 factors listed for the respondents to choose from. Barriers influencing work productivity were assessed with scores 0-4 scored as low, 5-9 as average, and 10-13 as high.

\section{Instrument reliability}

The instrument was pretested among 20 participants in a similar population (Olabisi Onabanjo University, Ogun State) to determine the reliability of the instrument, Cronbach's Alpha test for internal consistency was 0.73 .

\section{Data Management and Analysis}

Data were analyzed using IBM Statistical Package for Social Sciences (SPSS) version 21. Descriptive statistics such as percentage representations, charts, tables, and figures were used to present the results while the Pearson correlation coefficient was used to determine the relationship between the variables.

\section{Results}

The mean age of respondents was $38.68 \pm 11.04$, the majority of the respondents were females $(54.6 \%)$ compared to their male $(45.4 \%)$ counterparts. Most of the respondents were of Yoruba $(61.1 \%)$ origin. Members of staff that participated in this study were $(66 \%)$ while $(34 \%)$ were faculty members. Educational status revealed that the majority are learned with $87 \%$ having tertiary education (see table 1). 
Table 1. Frequency of Demographic Variables

\begin{tabular}{lcc}
\hline \multirow{2}{*}{ Variables } & \multicolumn{2}{c}{ Respondents in this study $\mathbf{N}=\mathbf{3 9 8}$} \\
\cline { 2 - 3 } Age (in years) & Frequency (n) & Percentage (\%) \\
$20-29$ & 156 & 12.23 \\
$30-39$ & 113 & 42.40 \\
$40-49$ & 46 & 30.70 \\
$50-59$ & 08 & 12.50 \\
$60-69$ & & 02.17 \\
Gender & 167 & 45.40 \\
Male & 201 & 54.60 \\
Female & & \\
Marital Status & 99 & 26.90 \\
Single & 248 & 67.40 \\
Married & 15 & 04.10 \\
Widowed & 06 & 01.60 \\
Divorced & & \\
Years of work & 283 & 76.90 \\
1-10 & 69 & 18.80 \\
11-20 & 16 & 04.30 \\
$21-30$ & & \\
Ethnicity & 225 & 61.10 \\
Yoruba & 104 & 28.30 \\
lgbo & 08 & 02.20 \\
Hausa & 31 & 08.40 \\
Others & & \\
Educational Status & 15 & 04.10 \\
No formal education & 18 & 04.80 \\
Primary & 320 & 87.00 \\
Secondary & $38.68 \pm 11.04$ & \\
Tertiary & & \\
\hline & Mean Age &
\end{tabular}

More than half $53.87 \%$ ) of the respondents had poor knowledge of nutrition while $46.13 \%$ had good knowledge of nutrition (see figure 1).

The mean score for dietary practice is (3.64 \pm 1.443$)$. The mean score signifies a poor dietary practice. Dietary practices measured among the respondents indicate that $49.4 \%$ of the respondents seek out nutrition information while $67.2 \%$ of the respondents read food labels before buying. Meanwhile, $71.8 \%$ do take breakfast and $83.4 \%$ claim to consume carbohydrates. More so, $32.3 \%$ of the respondents do not snack on foods, while $90.5 \%$ do not take alcohol (see table 2).

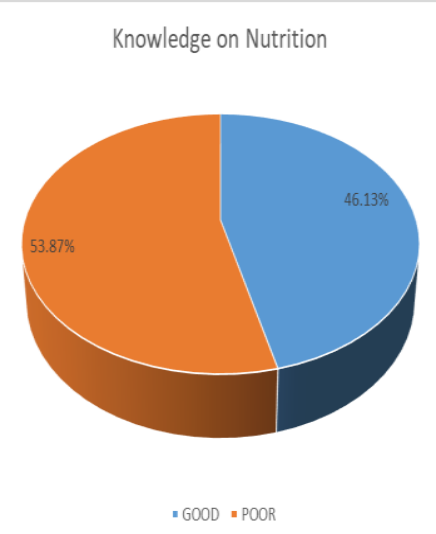

Figure 1: Knowledge on nutrition 
Table 2 Dietary Practices

\begin{tabular}{lcc}
\hline \multirow{2}{*}{ Variables for Consideration } & \multicolumn{2}{c}{ Respondents in this Study N=398 } \\
\cline { 2 - 3 } & Frequency (n) & Percentage (\%) \\
\hline I read food labels before buying at the mall or market & 247 & 67.2 \\
I eat breakfast every day & 264 & 71.8 \\
I complete three square meals per day & 137 & 37.2 \\
I do not take alcohol & 333 & 90.5 \\
I snack on food & 249 & 67.7 \\
How frequently do you consume carbohydrates? & 207 & 83.4 \\
How frequently do you consume protein? & 287 & 78.0 \\
How frequently do you consume vitamins? & 256 & 69.5 \\
How frequently do you consume fats and oil? & 236 & 64.1 \\
How frequently do you seek out nutrition information? & 182 & 49.4 \\
\hline
\end{tabular}

Table 3 indicates that many factors are influencing work productivity among workers at Babcock University: income $(57.9 \%)$, stress
(58.7\%), work environment (54.6\%), food eaten at work $(59.5 \%)$ while lifestyles choices and depression account for $52.2 \%$ respectively.

Table 3: Barriers to Work Productivity: Correct responses

\begin{tabular}{lcc}
\hline \multirow{2}{*}{ Variables for Consideration } & \multicolumn{2}{c}{ Respondents in this Study, N=398 } \\
\cline { 2 - 3 } & Frequency (n) & Percentage (\%) \\
\hline Income & 213 & 57.9 \\
Dietary pattern & 173 & 47.0 \\
Stress & 216 & 58.7 \\
Absenteeism & 112 & 30.4 \\
Health Related conditions & 207 & 56.3 \\
Work Environment & 201 & 54.6 \\
Sickness & 129 & 35.0 \\
Sleep hours & 195 & 52.9 \\
Food & 219 & 59.5 \\
Workplace Health Promotion & 192 & 52.2 \\
Lifestyle Choices & 192 & 52.2 \\
Depression & 131 & 35.6 \\
Inadequate Facilities & 210 & 57.0 \\
\hline
\end{tabular}

Table 4 shows that the level of knowledge computed mean and standard deviation score $(2.57 \pm 0.61)$ indicates that the knowledge of what constituted dietary practices in this study was poor $(25.7 \%)$, dietary practices as observed was also poor (3.64 \pm 1.443$)$ at $36.4 \%$ while barriers to work productivity was high $(11.34 \pm 5.286)$ at $87.2 \%$.

Table 4: Descriptive Summary of Composite Statistics

\begin{tabular}{lccccc}
\hline Variables & $\begin{array}{c}\text { Maximum } \\
\text { point scale }\end{array}$ & Mean & $\begin{array}{c}\text { Standard } \\
\text { deviation }\end{array}$ & $\begin{array}{c}\text { Standard } \\
\text { Error of Mean }\end{array}$ & $\begin{array}{c}\text { Prevalence } \\
\%\end{array}$ \\
\hline Knowledge & 10 & 2.57 & 0.61 & 0.032 & 25.7 \\
Dietary practices & 10 & 3.64 & 1.443 & 0.075 & 36.4 \\
Work productivity & 13 & 11.34 & 5.286 & 0.276 & 87.2 \\
\hline
\end{tabular}

Hypothesis One:

There is no significant relationship between nutritional knowledge and dietary practices of 
Babcock University staff. The study shows a perfect fit model and positive correlation (+1) and a coefficient of 0.75 translating to the magnitude of the relationship at $p=.154$. Therefore, we fail to reject the null hypothesis. Hence, there is no significant relationship between knowledge and dietary practices of Babcock University staff (Table 5).

Table 5: Correlation between knowledge and dietary practices

\begin{tabular}{lccc}
\hline Variables & $\begin{array}{c}\text { Pearson } \\
\text { correlation }(r)\end{array}$ & $\begin{array}{c}\text { Correlation } \\
\text { Coefficient }\left(r^{2}\right)\end{array}$ & $p$-value \\
\hline $\begin{array}{l}\text { Knowledge on Nutrition } \\
\text { Dietary practices }\end{array}$ & 1 & 0.75 & 0.154 \\
\hline $\begin{array}{l}\text { Work productivity } \\
\text { Dietary practices }\end{array}$ & 1 & 0.037 & 0.019 \\
\hline
\end{tabular}

Hypothesis Two:

There is no significant relationship between dietary practices and the work productivity of Babcock University staff. The study shows a perfect fit model and positive correlation $(+1)$ and a coefficient of 0.037 translating to the magnitude of the relationship at $p=.019$. Therefore, the null hypothesis is hereby rejected. Hence, there is a significant relationship between dietary practices and work productivity of Babcock University staff (see Table 5)

\section{Discussion}

Evidence from this study showed poor knowledge of nutrition by Babcock University staff. This was not expected as non-academic and academic members of staff of the University ought to have a good knowledge of their nutrition, especially the highly educated staff members even as $87 \%$ of the respondents in this study had tertiary education. This finding is similar to a study on nutrition-related knowledge conducted in the United States among teaching staff, which showed that only $3.0 \%$ of teachers correctly answered at least 4 questions on nutrition (15). This was similar to the finding among Head Start Teachers in Texas where none of the teachers could correctly answer all the five questions on nutrition (16). This highlights the need for nutritional educational interventions among the staff of educational institutions (17). This was supported by research that confirmed the need for intensive nutrition education to emphasize the importance of adopting good dietary practices among students, staff, and faculty members (18). In this current study, the respondents had poor dietary practices. This was similar to a study conducted among University staff in Southeast Nigeria that found that $69.0 \%$ took unhealthy snacks daily (19). Similarly, another study conducted among 57 teachers in Brazil revealed an excessive consumption of lipids (20). Poor dietary practices found in these studies highlight the need for interventions that should be targeted at correcting these practices. On alcohol consumption, we found that $9.5 \%$ of the respondents in our study consume alcohol. Alcohol consumption was also found among $8.5 \%$ of the 423 urban schoolteachers in a school in Ibadan, southwest Nigeria (21). This suggests the need for adequate health education for staff of educational institutions on the danger of alcohol consumption.

The findings from this study suggest that some factors such as income, stress, etc. influence work productivity, supporting a similar study conducted in Calabar confirming the impact of stress on nutrition and productivity among workers (22). Additionally, other factors like health and dietary practices act as barriers to work productivity. Research has suggested that numerous workplace interventions have shown significant improvements in employees' health and work productivity (23).

This study has equally shown that there is no relationship between nutritional knowledge and dietary practice, as opposed to a study conducted in Ireland among a randomly selected working population which indicated that higher nutritional knowledge is associated with better dietary practices, indicating a significant relationship between nutritional knowledge and dietary practices (24). Our finding was also at variance with a systematic review which found a significant, positive but weak association between knowledge on nutrition and dietary intake (25). However, this study showed a significant relationship between dietary practices and work productivity. Similarly, a study conducted in Turkey confirmed this finding, suggesting that there is a link between good dietary practice and high work productivity (26).

Strength and Limitation

This study has provided an insight into the dietary knowledge and practices in a tertiary institution in Southwest Nigeria. The findings could help the 
school administration, the local and international population in the design of interventions that will be aimed at improving nutritional knowledge and dietary practices to improve work productivity. However, since this study was based on selfreport, it is subject to social desirability bias as the respondents might tend to under-report poor dietary practices. Therefore, this limitation should be considered when interpreting this finding.

\section{Conclusion and Recommendation}

The study has shown that the majority of the respondents have poor knowledge of nutrition. It is suggested that there should be nutrition awareness programs. Workplace health promotion such as health talks, group discussions on nutrition should be incorporated into the school system.

\section{Declarations}

\section{Ethics Consideration}

Ethical approval was obtained from the Babcock University Health Research Ethical Committee (BUHREC617/17) before the commencement of the research. Confidentiality and anonymity were ensured. Informed consent was obtained from the study participants before data collection and the voluntary nature of the study was stressed.

\section{Consent for publication}

The authors hereby give consent for the publication of this work under the Creative Commons CC Attribution. Non-commercial 4.0 license.

\section{Availability of data and materials}

All data generated or analyzed in this study are included in this article and are available at any request.

\section{Competing interests}

No competing interests.

\section{Funding:}

None

\section{Authors' contributions}

Study design: OOE, MJO, AM

Data collection: AM, MBT, AE, CCF

Data analysis: OOE, MJO, AM

Study supervision: OOE, AK, CCF

Manuscript writing: AO, AE, UEN, MBT, FDD, OTD

Critical revisions for important intellectual content: AO, FDD, OTD, UEN

\section{Acknowledgments}

We would like to thank all the authors that contributed to the research.

\section{References}

1. Iyam MA, Inah GM, Udonwa RE, Etim JJ. Diet and Lifestyle: a panacea for achieving longevity in Ugep, Nigeria. European Journal of Biology and Medical Science Research. 2013 Dec;1(4):19-33.

2. Stress and Nutrition. Newsletter publication of Family Services Employee Assistance Programs (FSEAP). 2013. www.fseap.ca

3. Davis PC. Medical Definition of Nutrition. 2021 https://www.medicinenet.com/nutrition/definiti on.htm

4. World Health Organization. More than 820 million people are hungry globally. 2019. https://www.who.int/news/item/15-07-2019world-hunger-is-still-not-going-down-afterthree-years-and-obesity-is-still-growing-unreport

5. World Health Organization. Nutrition. 2021. https://www.who.int/health-topics/nutrition

6. Steyn NP, Nel JH. Dietary intake of adult women in South Africa and Nigeria with a focus on the use of spreads. Tygerberg: South African Medical Research Council. 2006 Feb. www.mrc.ac.za/chronic/kenyareport.pdf

7. Preedy VR, Watson R. Handbook of Disease Burdens and Quality of Life Measures. 2010. Springer.

https://link.springer.com/referencework/10.10 07\%2F978-0-387-78665-0

8. International Labour Organization. Poor workplace nutrition hits workers' health and productivity says new ILO report. 2005. https://www.ilo.org/global/about-theilo/newsroom/news/WCMS 005175/lang-en/index.htm

9. Caitlin Morgan Insurance Services. Food choices are determined by many factors with correct knowledge of nutrition being one of the most important. 2012 https://www.caitlinmorgan.com/poor-eating-habits-lack-ofexercise-impact-employee-productivityl

10.Kunene SH, Taukobong NP. Dietary habits among health professionals working in a district hospital in KwaZulu-Natal, South Africa. African Journal of Primary Health Care and Family Medicine. 2017 Feb 22;9(1):1-5. https://doi.org/10.4102/phcfm.v9i1.1364

11. Food and Agriculture Organization. Food and People: Dimensions of Need. 2021 http://www.fao.org/3/u8480e/u8480e04.htm 
12.Gbenga JB, Babalola JF. Exercise participation and diet monitoring in pursuit of healthy aging among the university staff members. Journal of Science and Technology (Ghana). 2016;36(3):75-82. https://doi.org/10.4314/just.v36i3.8

13. Contento IR. Nutrition Education: Linking Research, Theory, and Practice. 2007. Jones and Bartlett publishers. Boston.

14.Cochran WG. Sampling Techniques. New York: John Wiley and Sons, Inc; 1963.

15.Liu H, Xu X, Liu D, Rao Y, Reis C, Sharma M, Yuan J, Chen Y, Zhao Y. Nutrition-related knowledge, attitudes, and practices (KAP) among kindergarten teachers in Chongqing, China: A cross-sectional survey. International journal of environmental research and public health. $\quad 2018 \quad$ Apr;15(4):615. https://doi.org/10.3390/ijerph15040615

16.Sharma S, Dortch KS, Byrd-Williams C, Truxillio JB, Rahman GA, Bonsu P, Hoelscher D. Nutrition-related knowledge, attitudes, and dietary behaviors among head start teachers in Texas: a cross-sectional study. Journal of the Academy of Nutrition and Dietetics. 2013 Apr 1;113(4):558-62. https://doi.org/10.1016/j.jand.2013.01.003

17. Kollajtis-Dolowy A, Zamojcin K. The level of knowledge on nutrition and its relation to health among Polish young men. Roczniki Państwowego Zakładu Higieny. 2016;67(2).

18.Awosan KJ, Ibrahim MT, Essien E, Yusuf AA, Okolo AC. Dietary pattern, lifestyle, nutrition status, and prevalence of hypertension among traders in Sokoto Central market, Sokoto, Nigeria. International Journal of nutrition and metabolism. 2014 Jan 31;6(1):9-17. https://doi.org/10.5897/ijnam2013.0158

19. Mbah BO, Davidson GI, Eme PE, Udefi H. Assessment of obesity and dietary pattern of staff in a university in southeastern Nigeria. Nigerian Journal of Nutritional Sciences. 2015;36(1):12-7.

20.Rodrigues-Rodrigues T, Claudia Vieira Gomes A, Rodrigues Neto G. Nutritional status and eating habits of professors of health area. International Journal of Sport Studies for Health. 2018 Jan 31;1(1). https://doi.org/10.5812/intissh.64335

21.Fadupin GT, Adeoye A, Ariyo O. Lifestyle and nutritional status of urban school teachers in Ibadan, Nigeria. Nigerian Journal of Nutritional Sciences Vol. 2014 Mar;35(1).

22.Udonwa RE, Iyam MA, Inah GM. Impact of stress on nutrition and productivity (a study of Southern Cross River State, Nigeria). Int. J. Nurs. Midwife Health Relat. Cases. 2015;1(2):41-53.

23.Steyn NP, Parker W, Lambert EV, Mchiza Z. Nutrition interventions in the workplace: Evidence of best practice. South African Journal of clinical nutrition. 2009;22(3). https://doi.org/10.1080/16070658.2009.1173 4231

24.Geaney F, Fitzgerald S, Harrington JM, Kelly C, Greiner BA, Perry IJ. Nutrition knowledge, diet quality, and hypertension in a working population. Preventive Medicine Reports. 2015 Jan 1;2:105-13. https://doi.org/10.1016/i.pmedr.2014.11.008

25.Spronk I, Kullen C, Burdon C, O'Connor H. Relationship between nutrition knowledge and dietary intake. British journal of nutrition. 2014 May;111(10):1713-26. https://doi.org/10.1017/s0007114514000087

26.Bor H. The Relationship Between Nutrition and Worker Efficiency. Turkish Journal of Family Medicine and Primary Care. 2020;14(2):305-11. https://doi.org/10.21763/tifmpc.642063 